\title{
From the Languages of Art to mathematical languages, and back again ${ }^{1}$
}

\author{
Caroline Jullien
}

Archives Henri Poincaré CNRS UMR 7117 / Université de Liège. Belgique

Caroline.Jullien@univ-nancy2.fr

\begin{abstract}
Mathematics stand in a privileged relationship with aesthetics: a relationship that follows two main directions. The first concerns the introduction of mathematical considerations into aesthetic discourse. For instance, it is common to mention the mathematical architecture of certain artistic productions. The second leads from aesthetics to mathematics. In this case, the question is that of the role and meaning that aesthetic considerations may assume in mathematics. It is indeed a widely held view among mathematicians, of whatever socio-historical context, not only to see their discipline as presenting a strong aesthetic dimension, but also to consider that this dimension plays a fundamental role in the process of developing and understanding mathematics. The main ambition of this paper is to show how Nelson Goodman's aesthetics can be used to justify this point of view and to propose a thesis concerning the aesthetic functioning of mathematics. This first result allows to resituate Goodman's aesthetics within a very classical tradition that will be described. Finally, the underlying ambition is to show the keys provided by Goodman's theory for the philosophy of mathematics.
\end{abstract}

Keywords: mathematics; aesthetics; philosophy of mathematics; Goodman; symbolization; symptoms of the aesthetic.

Resumen. De los Lenguajes del Arte a los lenguajes matemáticos y de vuelta

Las matemáticas tienen una relación privilegiada con la estética, una relación que sigue dos direcciones principales. La primera se refiere a la introducción de consideraciones matemáticas en el discurso estético. Por ejemplo, es usual mencionar la arquitectura matemática de ciertas producciones artísticas. La segunda va desde la estética a las matemáticas. En este caso, la cuestión es la del papel y el significado que las consideraciones estéticas pueden tener en las matemáticas. De hecho, una perspectiva muy extendida entre los matemáticos, sea cual sea su contexto socio-histórico, es la de ver su disciplina no solamente presentando una fuerte dimensión estética, sino también considerar que esta dimensión juega un papel fundamental en el proceso de desarrollo y comprensión de las matemáticas. El principal objetivo de este artículo es mostrar cómo la estética de Nelson Goodman puede utilizarse para justificar este punto de vista y proponer una tesis respecto al funcionamiento estético de las matemáticas. Éste primer resultado permite resituar la

1. I wish to thank the two anonymous referees for their insightful comments. 
estética de Goodman en una tradición muy clásica que será descrita. Finalmente, el objetivo subyacente es el de mostrar las claves proporcionadas por la teoría de Goodman para la filosofía de las matemáticas.

Palabras clave: matemáticas; estética; filosofía de las matemáticas; Goodman; simbolización; síntomas de lo estético.

\section{Summary \\ 1. Introduction 4. Conclusion \\ 2. Historical Context References}

3. Goodman and Mathematics

\section{Introduction}

In 1997, Nelson Goodman was awarded the title of doctor Honoris Causa by the university of Nancy 2. On this occasion, Goodman clearly expressed his wish that his theory of aesthetics should be applied to mathematics. This project is by no means incongruous - on the contrary, it is entirely justified. The approach Goodman pursues throughout his Languages of Art (1968) aims to provide an account of the aesthetic functioning of symbol systems in general, whether they originate in the arts or in the sciences. So there is a place for mathematics among the applied studies of Goodman's aesthetics. Moreover, construing mathematics as an object of aesthetic study is by no means a novelty, quite the reverse. Indeed, until the 18th century, mathematics were fully part of what would today be called aesthetics. For a long time, this science played a double role, both as a model for the description of aesthetic properties and as a privileged field of inquiry for appraising the relevance of aesthetic theories.

The purpose of this study is threefold: it aims to show that Goodman's analytical tools can be used to construct an argumentatively supported thesis concerning the aesthetic functioning of mathematics, and thereby to account for the role that mathematicians commonly ascribe to aesthetics in the process of developing and understanding mathematics (see, for example, Poincaré 1908, 45-53, 128; Poincaré 1905, 35-37; Rota 1997, 182; Hardy 1940). It also aims to show how, in the final analysis, Goodman's aesthetics can be resituated within an extremely classical philosophical tradition. Finally, the third objective is to shed light on the keys supplied by Goodman's theory for the philosophy of mathematics. The first section is introductory. Properly speaking, its structure is not historical. Its purpose is merely to supply some information that allows grasping the problem of the relationship between mathematics and aesthetics within its historical context. In the second section, I will take on this question on the basis of Goodman's work. 


\section{Historical Context}

As early as in ancient Greece, attention was called to the affinities between mathematics and aesthetics, notably in Aristotle's conception of beauty. Properly speaking, Aristotle does not formulate a theory of beauty, yet he describes the special characteristics of beauty. And the description he gives of them is found in Metaphysics M, i.e., in the book devoted to mathematics:

(...) those who assert that the mathematical sciences say nothing of the beautiful or the good are in error. For these sciences say and prove a great deal about them; if they do not expressly mention them, but prove attributes which are their results or their definitions, it is not true to say that they tell us nothing about them. The chief forms of beauty are order and symmetry and definiteness, which the mathematical sciences demonstrate in a special degree. And since these (e.g. order and definiteness) are obviously causes of many things, evidently these sciences must treat this sort of causative principle also (i.e. the beautiful) as in some sense a cause. (Metaphysics M 1078 a 31b5)

The criteria Aristotle suggests in order to define beauty are order, symmetry and definiteness, and in the Poetics we find justifications of this selection based both on empirical examples (things that we find beautiful satisfy these criteria) and on theoretical explanations:

Again, a beautiful object, whether it be a living organism or any whole composed of parts, must not only have an orderly arrangement of parts, but must also be of a certain magnitude; for beauty depends on magnitude and order. Hence a very small animal organism cannot be beautiful; for view of it is confused, the object being seen an almost imperceptible moment of time. Nor, again, can one of vast size be beautiful; for as the eye cannot take it all in at once, the unity and sense of the whole is lost for the spectator; as for instance if there were one a thousand miles long. As, therefore, in the case of animate bodies and organisms a certain magnitude is necessary, and a length which can be easily embraced by the memory. (Poetics $1450 \mathrm{~b} 40$ )

The characteristics of beauty are thus useful properties that yield an optimal perception of the object they apply to. So it would seem that Aristotle's standards concerning beauty amount to standards relating to perception, and thus they describe the conditions of understanding. Men can understand what is ordered, measured and delineated far better than what is chaotic, without clear boundaries, etc. In other words, the things that are beautiful are the ones that can be described in their entirety. From an Aristotelian perspective, in contrast with a Platonic point of view, beauty's fundamental usefulness is not as a revealer of truth but as a source of understanding. In this sense, beauty is a cognitive property rather than an aesthetic one.

Aristotle establishes a narrow and singular relationship between mathematics and beauty: mathematics themselves are beautiful; furthermore, they provide a model for beauty. Possibly further still, by exemplifying beauty they shed light on their cognitive mechanisms. If men are able to understand and 
develop mathematics, it is because they are beautiful in the sense that they are governed by order, measure and limitation. In the context of this conception of beauty, aesthetic analysis in philosophy of mathematics is justified by reasoning as follows: if mathematics are beautiful in the sense suggested by Aristotle, and if this property is the cause of their intelligibility, then it makes sense to take an interest in the aesthetic aspect of mathematics in order to better understand the processes behind their development and understanding them. In other words, in an Aristotelian context, the relevance of aesthetic analysis to the philosophy of mathematics is justified by a coherent argument.

Broadly speaking, traces of this Aristotelian heritage concerning beauty can be found until the 18th century. Let me be more specific. The main characteristics of beauty in circulation, such as the principle of unity in variety, symmetry and harmony, apply to mathematics. The authors studying these characteristics used mathematics both to clarify these properties and to test their selection of aesthetic criteria for relevance. In particular, this means that mathematics are pressed into service both as a model for conceiving aesthetic criteria, and as a field of experimental inquiry used to test the relevance of theoretical and aesthetic choices. Let us consider an example by Irish philosopher Hutcheson, found in his Inquiry into the Origin of our Ideas of Beauty and Virtue (Hutcheson 1725). He devotes special attention to the qualities of objects that elicit or cause the idea of beauty. Hutcheson then begins by establishing the principle of uniformity in variety:

The Figures which excite in us the Ideas of Beauty, seem to be those in which there is Uniformity amidst Variety. [...] But what we call Beautiful in Objects, to speak in the Mathematical Style, seems to be in a compound Ratio and variety: for that where the uniformity of bodies is equal, the beauty is as the variety; and where the variety is equal, the beauty is as the uniformity. [...]

First, the variety increases the beauty in equal uniformity. The beauty of an equilateral triangle is less than that of the square; which is less than that of a pentagon; and this again is surpassed by the hexagon [...].

The greater uniformity increases the beauty amidst equal variety, in these instances: an equilateral triangle, or even an isosceles, surpasses the scalenum: a square surpasses the rhombus or lozenge, and this again the romboids, which is still more beautiful than the trapezium, or any figure with irregular curve sides. (Hutcheson 1725, 17-18)

This quotation is a mere sample; Hutcheson's text abounds with mathematical examples. What must be stressed is the double, or possibly even the triple role played by mathematics in this work. Indeed, they function as methodological model: Hutcheson gives his definitions a quasi-mathematical structure. For example, he does not merely state the principle of uniformity in diversity, but qualifies it by introducing a concept of gradation: the degree of variety being equal, greater uniformity increases beauty, and vice-versa. This role is very likely the least interesting from the standpoint of my current subject: the suc- 
cess and progress of mathematics in the 18th century probably explains the desire to harness their methods. The second role is that they come across as a source of inspiration when conceiving aesthetic criteria. The whole text in which Hutcheson describes the qualities that are the cause of beauty is entirely based on mathematical examples. These are the fuel of his inquiry and enable him to fine down and fledge out the primary principle of unity in variety. Finally, mathematics come across as an area where the results reached by Hutcheson in his Inquiry can be applied. Indeed, an entire section is devoted to the study of mathematical beauty, of the beauty of theorems, corollaries, propositions, etc.

Note that the treatment of mathematics when exploring aesthetic properties is not designed to prove that mathematics are beautiful, which would seem not to require a demonstration, but aims to explain why we find them beautiful. In this sense, mathematics are used to justify the characteristics of beauty. In this regard, for example, the Swiss philosopher and mathematician Jean-Pierre Crouzas writes on the principle of unity in variety:

It is also in the speculations of this science [mathematics] more than in any other, that the mind rapturously discovers uniformities that always sustain themselves among infinite diversities. I will not go on to give examples of this truth, those to whom the Beautiful Sciences are known will instantly recall them, and those who have not yet learned them would not understand them. (Crouzas 1724, 190)

The influence of mathematics on speculations concerning beauty, and more generally on the analysis of aesthetic properties, has already been subjected to serious scrutiny ${ }^{2}$. Yet, to my knowledge, none of these studies highlight the fact that mathematics have in return been a subject of aesthetic inquiry. In Cassirer's The Philosophy of the Enlightenment (Cassirer 1932), for instance, the role mathematics have sometimes played as a model in the history of aesthetics is clarified, but the fact that mathematics themselves (as well as works of art) were the subject-matter of aesthetic inquiries is never mentioned. I refrain from explaining at length the reasons of this almost systematic oversight. I will only mention that there are two types of explanation. One of institutional nature: the formation of the system of the fine arts grouped together on the basis of aesthetic concerns on the one hand, and the dogma of a "pure» science on the other, led to a clear institutional separation between art and science. And there is a theoretical aspect rooted in the Kantian opposition between aesthetic and logical judgments (Jullien 2008, 31-46).

That being so, although the aesthetic theories conceived since the beginning of the 19th century turn away from mathematics, mathematicians

2. See, among others: Kristeller, Paul Oskar, Renaissance Thought and the Arts, Princeton, Princeton University Press, 1999; Kivy, Peter, The Seventh Sense, A Study of Francis Hutcheson's Aesthetics and its Influence in Eighteenth-Century Britain, New York, Burt Franklin \&Co. Inc, 1976 or Le Lionnais, François, Les grands courants de la pensée mathématique, Paris, Blanchard, 1962. 
themselves continue to give accounts of what they view as the essential role of the aesthetic aspect of mathematics. On this topic, Poincaré puts forward a genuine, coherent and argued thesis. Not only does he defend the aesthetic aspect of mathematics from an evaluative or quantitative point of view (mathematics possess aesthetic properties of their own), but he also defends the functional role of aesthetics in the development and understanding of mathematics $^{3}$. The meticulous analysis of Poincaré's thesis can serve to define the stakes and approaches that are intrinsic to the study of aesthetics in mathematics. For example, Poincaré's thesis concerning the evaluative aspect of the aesthetics of mathematics is only valid within a framework defined by a metaphysical assumption according to which nature is the source of all beauty, one of this assumption's corollaries being an ontological assumption concerning the status of beauty. For its part, Poincaré's thesis on the role of aesthetics is based on a methodological assumption according to which mathematics are the only tool suitable to describe the world of natural phenomena (Jullien 2012). Poincaré's argument is therefore rather costly in terms of ontological, metaphysical and methodological constraints. This does not affect its soundness; it does however make it difficult to generalize. The genesis of Poincaré's thought is not based on a specific theory of aesthetics; this may be one of the reasons why he is compelled to introduce assumptions. In his defence it can be said that finding a strong theory of aesthetics that can be applied to mathematics is no easy task. Indeed, at least two conditions apply if one is to successfully carry out an aesthetic analysis of mathematics in the hope of testing the legitimacy that mathematicians grant to the aesthetic aspect of mathematics. First, analytical tools not linked to a specific ontology are required: the importance given to aesthetics in mathematics is not idiosyncratic to a group of mathematicians who subscribe to a specific ontology of mathematics. If, therefore, aesthetic analysis aims to remain as broadly relevant as possible, it must not restrict its sphere of validity to a given family within the ontology of mathematics. Second, given the powerful cognitive role aesthetics are granted in mathematics, the choice of an aesthetic analytical tool must also account for how aesthetics can contribute to our understanding. In short, one should be in possession of a theory of aesthetics both economical in ontological terms and explicit regarding the relationship between the functioning of aesthetics and cognitive value. This is where Nelson Goodman's aesthetics comes in.

3. One can read for example, in Science and Method: «Now, what are the mathematical entities to which we attribute this character of beauty and elegance, which are capable of developing in us a kind of aesthetic emotion? Those whose elements are harmoniously arranged so that the mind can, without effort, take the whole without neglecting the details. This harmony is at once satisfaction to our aesthetic requirements, and an assistance to the mind which it supports and guides.» (Poincaré 1908, 59). 


\section{Goodman and Mathematics}

In Languages of Art, Goodman presents a general theory of symbols and he also develops a symptomatological approach to the aesthetic functioning of symbol systems. The thesis that I defend here is a double one: it purports first to substantiate the validity of a Goodmanian analysis of mathematics, and second to highlight the role mathematics can play in interpreting Goodman's aesthetics. My approach might therefore seem unconventional in some respects. Indeed, it is often said that there is a before and an after Goodman, that his work marks a significant turning point in the history of aesthetics. I do not dispute this. On the other hand, I believe that when it is considered from the standpoint of the history of the relations between mathematics and aesthetics, Goodman's theory is in fact very classical.

The theory of aesthetics developed by Goodman fits within his broader theory of symbolization. His project consists in analyzing the referential operations of symbol systems, from which he proposes to deduce the operations of aesthetics. His original assumption is that although very much in evidence in the field of art, aesthetic operations are not the exclusive province of works of art; they can be present in a wide variety of symbol systems, including also scientific symbol systems ${ }^{4}$. Hence, there is no direct argument against applying Goodman's theory to mathematics. Indeed, from a technical point of view, one can show without the slightest difficulty that mathematics may be construed as symbol systems in Goodman's sense.

More precisely, mathematics can be construed as a non-disjunctive union of symbol systems, all of which are constructed according to the same elementary or basic symbol scheme. The latter would be made up from the usual marks : a literal and numerical alphabet (the first letters of the classical alphabet, $a, b$ and $c$ are often earmarked for constants, the letters $f, g, h$ for functions and the final letters $\mathrm{x}, \mathrm{y}, \mathrm{z}$ for unkowns), operators $(=,+, /)$, quantifiers or, as well as syntactic construction rules (e.g., the real addition of two numbers is written by placing both numbers on either side of the + operator).

4. «(..) my study ranges beyond the arts into matters pertaining to the sciences, technology, perception, and practice. Problems concerning the arts are points of departure rather than of convergence. The objective is an approach to a general theory of symbols.» $(L A, \mathrm{xi})$. See also $L A, 262-265$.

5. Broadly speaking, a symbol system is made up of a set of basic (atomic) elements, a list of explicit combinatory rules used to construct complex elements from the atomic elements and rules for their interpretation. The "mark» is the material aspect of the atomic or complex elements. For example, an «a» is a mark in the symbol system of the Latin alphabet. A character is the class defined by a set of marks that are equivalent to one another. For example, any inscription of «a» belongs to the character «a», its font or colour notwithstanding. Finally, Goodman draws a distinction between symbol scheme and symbol system by stipulating that in the first case only syntactic considerations come into play, whereas in the second semantic considerations also apply. In other words, a symbol system is a symbol scheme correlated with a field of reference (See all $L A$ and especially, Ch.4 «The Theory of Notation,» $L A, 127-173)$. 
There is no harm in construing this scheme as the basic scheme of all mathematical symbol systems. The worst this could result in is a degree of cumbersomeness and redundancy, present also in other kinds of symbol systems. A primary analysis leads one to divide the various mathematical symbol systems into three main families:

1) The family of applied mathematics, in which the characters of the scheme are interpreted in relation to the physical world of natural phenomena.

2) The family of the various ontological or methodological approaches to mathematics, in which the interpretation or the presentation of a mathematical object is restricted by ontological or methodological constraints.

3) The family of particular subsets of mathematical objects that are interpreted according to a predefined list of axioms or properties.

If one considers a symbol system obtained by referring the basic scheme to one of the members of the first family, it is possible for some of the characters to be vacant. For example, an equation describing a physical phenomenon for which a negative root could not be interpreted. In this case, two sorts of vacancy are possible:

- A semantic vacancy: some characters have no concordant phenomenon, - A syntactic vacancy: some phenomena do not concord with any character.

In the second family, the characters of the scheme are referred and interpreted according to the constraints linked to a specific approach. For example, the quantifiers («there exists» or «for all») have no concordant elements in the context of a constructivist mathematical system.

Finally, the third family, which is the largest, comprises the particular systems that can be obtained on the basis of specific rules or axioms. For example, if the basic scheme refers to whole numbers, then the square root of two, which is a valid character within the symbol system, does not comply with any element of the set of natural whole numbers. The combinatory rules will receive different interpretations depending on the sub-set under consideration: such is the case, for example, of the addition of two whole numbers contrasted with the addition of two vectors of the same plane. These families are clearly not independent from one another. The interpretation of a symbol within a system belonging to the first family (implying that one uses it to refer to the physical world) is dependent on a prior interpretation within a system belonging to the third family, and possibly to the second as well.

In any event, the initial conditions required in order to apply Goodman's aesthetics, i.e., a given symbol system, are satisfied by mathematics.

In Goodman's work, the purpose of the analysis of the languages of art and of symbolization in general is not to provide an ontological explanation of reference - to determine why such and such a predicate applies to such and 
such an object - but to pin down the various types of reference. This ontological parsimony is especially worthwhile regarding the aesthetic analysis of mathematics, since it provides a glimpse of what results might be obtained independently from any ontologically restrictive conception of mathematics. Finally, Goodman's aesthetics is squarely functional and cognitive in nature, which leaves room for a possible argumentative framework supporting the thesis of aesthetics' cognitive role in the process of demonstration. From a theoretical standpoint, the choice of Goodman's theory in order to describe the aesthetic aspect of mathematics is justified.

So what comes to light from effectively applying Goodman's theory to mathematics? The results that I came to and discussed in Esthétique et mathématiques - une exploration goodmanienne (Jullien 2008) (Aesthetics and mathematics - a goodmanian exploration) first show that Goodman's theoretical instrumentarium can be adapted to mathematics. Goodman's aesthetics is based on a symptomatology. When discussing the modes of symbolization, Goodman identifies five symptoms revelatory of an aesthetic dimension ${ }^{6}$. First of all, there are the two syntactic requirements termed syntactic density and relative syntactic repleteness, a semantic requirement called semantic density, and finally two requirements pertaining to reference, exemplification, which is a mode of reference, and multiple and complex reference, which is a route of reference. I propose to recall the definition of each of these symptoms while attempting to show how they can be put to use in mathematics.

\section{a) Syntactic density (LA, 135-137)}

Syntactic density characterizes symbol schemes that offer no means of drawing up a complete list of each and every character entering into their composition. In a syntactically dense scheme, one cannot comprehensively review its characters or isolate them from each other.

If one construes mathematics as a symbolic language, then they are plainly not syntactically dense. Indeed, if only those mathematical objects that are linked to linguistic notations and mathematical symbolism proper (operator symbols, quantifiers) are taken into consideration, with mathematical figures being disregarded, then it is always possible to ascertain whether a mark belongs to a single character by examining either its intrinsic structure or its context. In other words, one can always isolate each character from the system, so syntactic density is not satisfied. This deficiency, if it truly is one, should not be viewed as an aesthetic shortcoming, but only as a singular trait due to the fact that mathematics can be construed as a language and are therefore not syntactically dense. However, mathematics are not merely a language, as for-

6. The first four symptoms are defined in $L A, 252-254$; the fifth, multiple and complex reference, is coined in $W W, 91$. Moreover, in case a reminder is needed, a symptom is not a decisive criterion, but a clue that tends to reveal something ( $L A, 254-255)$. 
malism once believed: the use of figures can be an essential part of a demonstration ${ }^{7}$.

\section{b) Relative syntactic repleteness (LA, 228-230)}

Another syntactic requirement listed among the symptoms is relative syntactic repleteness. Relative syntactic repleteness is a property that applies to pictorial systems, which allows to establish a gradation between maximum saturation and minimum saturation (attenuation). Saturation is measured according to the number of syntactic aspects that are contingent to the interpretation of the system. In a word, saturation is characterized when all the syntactic aspects of a system, or the better part thereof, are relevant to the system's operation. Goodman's famous example consists in drawing a comparison between the curve of an electrocardiogram and a sketch of mount Fujiyama by Hokusai $(L A, 229)$. These two systems, he explains, might be perfectly identical, but whereas in the curve of the electrocardiogram only the relative height of the $\mathrm{x}$ and $y$ axes are relevant, in the sketch of mount Fujiyama each and every aspect plays a part: the fineness or thickness of line, the colour of the ink, etc. The sketch is saturated, the curve is attenuated.

Since it is a manifestly syntactic property, applying it to linguistic systems would seem not to make sense. Indeed, calligraphy and its offshoots aside, most texts, whether they are of a literary nature or not, are attenuated in the sense that their symbolic functioning is not altered by modifying a wide variety of syntactic properties (the font, the medium, or the colour of the ink can all be changed without consequence, for example). In a text, the distinction between essential and contingent syntactic aspects is generally clear. But does the same apply to the notation of mathematics? One of the differences between mathematics as a symbol system and any given symbol system is that, in the first case, the rules for combining the symbols afford more freedom than in the second. In linguistic systems, the rule of linear concatenation prevails. In the case of mathematics, symbols are combined according to various laws or using operators, with the properties of the latter offering several different notational possibilities for the same object. For example, in the real closed field R, a polynomial $\mathrm{P}(\mathrm{x})$ may be noted $\mathrm{x}^{4}+9 \mathrm{x}^{5}-12$, or $-12+\mathrm{x}^{5} 9+\mathrm{x}^{4}$ or a number of other different ways generated thanks the commutativity and symmetry of multiplication and addition in R. In a purely linguistic system, the degree of latitude available when selecting a syntactic symbol is restricted to the mark, i.e., inscription. Such choice has no incidence on the system's functioning. In mathematics, the breadth of choice is greater, and one can select not only the mark, but also the reciprocal organisation of the symbols. So introducing the concept of saturation in mathematics as a symbol system is justified.

7. I have shown elsewhere that the demonstrative role that certain types of mathematical figures can play convincingly warrants introducing syntactic density as an analytical tool (Jullien 2008, 199-255). 


\section{c) Semantic density (LA, 152-154)}

Obviously, semantic density is the semantic counterpart of syntactic density. The symptom of semantic density thus characterizes systems featuring multiple characters, with concordance-classes (i.e., the set of labels with which a character concords) ordered in such a way that between any two of them, there is always a third. Broadly speaking, semantic density applies to systems in which the freedom of interpretation is very extensive. This breadth derives from the categorial overlap that density implies. Semantic density is inherent to all linguistic systems, although it can vary: multiple interpretations would be out of place when reading a recipe or a specification sheet, whereas understanding the functioning of a literary or poetic text positively requires that they should be taken into account. If mathematics are not strictly reducible to a linguistic system, neither are they entirely foreign to such a type of system. And as such, they are semantically dense. I support the thesis that density in mathematics is by no means contingent, but rather plays a constitutional role (Jullien 2011). In this regard, I side with Poincaré's maxim that mathematics are the art of giving the same name to different objects ${ }^{8}$. It is the semantic density of mathematics or, in other words, the richness of their symbolic fabric that makes it possible to draw relationships between very different objects.

\section{d) Exemplification (LA, 52)}

Exemplification is a specific mode of reference that links an object with a label that applies to it: an object exemplifies a label if and only if the object refers to the label and the label denotes the object (i.e., applies to it). Broadly stated, one speaks of exemplification when one highlights a particular aspect of an object. In mathematics, exemplification is a recurring mode of reference. In the equality « $\mathrm{x}=2 \mathrm{n} »$, for example, the internal relationship expressed by the equality predicate usually exemplifies a label such as «to be even». Exemplification plays an essential role in any process of mathematical demonstration: in fact, it comes across as a demonstration technique in its own right. Indeed, the better part of mathematical demonstrations progress through what could be called sampling steps, which consist in transforming a given inscription until a sample of a particular label is obtained. I will return to this point later.

A straightforward example of the use of exemplification in mathematics can be found in problems of indeterminate structure. Take the following rational function:

$$
f(x)=\frac{3 x^{2}-10 x-7}{x-4}
$$

8. «(..) mathematics is the art of giving the same name to different things» (Poincaré 1908, 34). 
When studying the behaviour of this function when $\mathrm{x}$ tends towards infinity, an elementary valuation establishes that the infinite limit of this function is infinity. Now, if one wishes to understand why and how this function tends towards infinity when $\mathrm{x}$ tends towards infinity, the notation selected above to represent function $\mathrm{f}$ is of little help. However, a simple transformation makes it possible to rewrite the function as follows:

$$
f(x)=3 x+2+\frac{1}{x-4}
$$

These two notations are strictly equivalent: they share the same extension (same truth value) and intension (they both represent the same function). Yet, contrary to the first, the second notation makes it possible to understand how the function behaves at infinity. Indeed, the second notation makes plain the fact that the function possesses an oblique asymptote with an equation $y$ $=3 \mathrm{x}+2$ when $\mathrm{x}$ tends towards infinity. In other words, the perception of the function's behaviour at infinity is optimised by the second representation (i.e., the second equation's notation) of the function. The difference between these two logically equivalent notations is exemplificational: the second notation is a sample of the label "to have an oblique asymptote», of which the first is merely an instance. This example also makes it possible to understand the interpretation of the repleteness requirement in mathematics. The syntactic structure of the second notation is replete, in the sense that altering the organisation of its syntax would affect its interpretation, i.e., its proper symbolic functioning.

\section{e) Multiple and complex reference (WW, 68)}

Finally, Goodman introduces multiple and complex reference, which points to the multiple varieties of referential species that apply to any single object. Multiple and complex reference occurs when «a symbol performs several integrated and interacting referential functions, some direct and some mediated trough other symbols» (WW, 68).

Goodman's inquiry into the symptoms of the aesthetic follows an analysis of the various types of reference, in particular denotation, exemplification and their main varieties (representation, description, expression, etc). In order to study them, Goodman distinguishes and isolates these different varieties of reference. This methodological imperative does however present the disadvantage of suggesting a complete mutual autonomy and independence of these types of reference. Yet a symbol may very well refer by following a referential chain or path made up of several referential steps, each of which is arrived at through different types of reference. Moreover, the artificial segmentation of the different modes of reference leads to a view of reference as being static, whereas the process of reference is quite the opposite: a dynamic process throughout which the referential varieties of the same symbol may interact with each other. Where this obtains, multiple and complex reference 
occurs. Multiplicity points to the fact that a symbol may have several referential functions. These can be unilateral or not: a symbol can exemplify several labels, it can also work as a label under some facets and as a sample under others. Complexity brings into play a kind of transitivity of reference, or at the very least reflects a form of indirect reference. Reference is not always transitive: the fact that symbol $S$ refers to predicate $T$, which in turn denotes $S^{\prime}$, does not necessarily imply that $S$ refers to $S^{\prime}$. But when such is the case, i.e., when reference truly is transitive, then one can speak of complex reference. In this context therefore, complexity does not carry connotations of complication (each and every reference is individually straightforward), but points to the number of referential steps that lead from a symbol to that which it refers to.

In mathematics, the use of the dual referential status (i.e., exemplificational and denotative) of its symbols makes it possible to build a demonstration. In other words, mathematical reasoning is constructed from a web of multiple and complex references. Mathematical demonstrations cannot be reduced to a mechanical chain of arguments following a direct referential path (i.e., without inverting denotational hierarchy). Indeed, when one wishes to demonstrate that a result applies to all objects of a specific class, one selects any object belonging to the class in question as representative of its class, and makes use of what it can be shown to exemplify. The representative of a class has both a denotative function (it denotes the elements of its class), and an exemplificational function (it refers to one of its aspects).

My purpose is not to provide a detailed interpretation of all these symptoms, but to show what the use of this symptomatology can contribute to an analysis of mathematical reasoning. I should mention straight away that the role these five symptoms play is apparent throughout all of mathematics' operative modalities. For example, one can show that many mathematical demonstrations rely on a multiple and complex referential chain, whose assembly relies on sampling phases. These in turn are made possible, first by drawing on semantic density, and second by a process of saturation. Consider a classical theorem structure: we are presented with a series of hypotheses and a conclusion. If we term $\mathrm{H}$ the label that can be constructed from the hypotheses of a mathematical proposition, and $\mathrm{C}$ the label that applies to the conclusion of this proposition, then the process of verifying the proposition can be represented as follows: we select an object such as $\mathrm{H}$ applies to it and we transform the object using valid rules in order to make explicit the object's possession of $\mathrm{C}$. So the first step is a matter of denotation (the task is to select any object as long as it is denoted by $\mathrm{H}$, i.e., as long as $\mathrm{H}$ applies to it), whereas the second step is a matter of exemplification (the task is to select among the possible notations those that exemplify C). The same symbols thus take on different referential functions throughout the course of the demonstration. Drawing on semantic density expresses the possibility of choosing between the various concordant elements of the same character. Finally, exemplification comes into play through a process of saturation when selecting the 
syntactic representative of a mathematical object. For example, the classical demonstration of the following proposition: «all differentiable real functions are continuous» illustrates the process described above. In this instance, the label $\mathrm{H}$ is «to be differentiable (and real)» and the label $\mathrm{C}$ is «to be continuous». The demonstration is direct, it consists in taking into consideration any function $\mathrm{f}$ denoted by the label "to be differentiable». This property $\mathrm{f}$ is then translated into mathematical notation (exploitation of semantic density), then the notation is transformed (repleteness process) until fs possessing the label $\mathrm{C}$ : «to be continuous» has been made plain; in other words, until a notation has been arrived at that allows for the exemplification by $\mathrm{f}$ of label $\mathrm{C}$. The proposition is then proved.

\section{Conclusion}

That the interpretation of Goodman's aesthetics does not give rise to difficulties is one thing, understanding what this approach to mathematics can contribute is another. I would say that beyond offering a means of showcasing the aesthetic functioning of mathematics and understanding their cognitive role, the Goodmanian analysis of mathematics' main contribution is to account for certain phases and connections in mathematical reasoning that are inaccessible to standard logic. In particular, exemplification makes it possible to study the role of a mathematical symbol in the context of a chain of reasoning from the standpoint of its intension, whereas standard logic would only take its extension into account. The fact that Goodman's theory provides a key to certain phases of mathematical reasoning makes it possible to situate Goodman's aesthetics within the historical perspective introduced in the first part of this paper. Indeed, the list of the five symptoms of Goodman's aesthetics, which is the framework of his theory, remains fairly programmatic: Goodman is rather sparing in his remarks concerning the interpretation of these symptoms. The detailed interpretation that I needed to construct, bearing in mind the concrete use I wished to make of Goodman's symptoms, yields a sort of feedback from mathematics to Goodman's theory. Indeed, by sharpening Goodman's theoretical instrument on mathematics, one manages to fine down and specify the symptoms, particularly in the case of exemplificational systems. These cases are not studied by Goodman and he merely indicates a slight modification of his terminology $(L A, 233-234)$. In fact, things are far less straightforward and all the terms in play need to be recast (Jullien 2008, 17-19). As the backdrop of this investigation, mathematics have nonetheless proven to be a most propitious field for understanding Goodman's programme. In this respect, one finds oneself in the wake of an extremely classical, pre-Kantian and post-Aristotelian tradition that credits mathematics with a dual role as a model and an object of analysis for aesthetics.

I therefore construe the relationship between Goodman's aesthetics and mathematics as being dialectic rather than unilateral. Mathematics can be pressed into service by Goodman's aesthetics in order to interpret and under- 
stand the symptoms of the aesthetic, and Goodman's aesthetics are an analytical tool for mathematics. In this dialectic we encounter once more the nature of the bond that has linked mathematics to aesthetics from ancient Greece until the end of the 18th century. My approach aims to resituate this dialectic within the modern framework of the issue of the relationships between mathematics and aesthetics, whose boundaries can be safely drawn using Poincaré's and Goodman's approach.

\section{References}

Aristotle. Metaphysics. English translation, introduction and commentary by W.D. Ross, volume II. Oxford: Oxford University Press, 1924.

- Poetics. New York: Cosimo Classics, 2008.

Cassirer, Ernst (1932). Die Philosophie der Aufklärung, Tübingen: J.C.B. Mohr. French translation by Pierre Quillet, La philosophie des lumières. Paris: Fayard, 1976.

Crouzas (de) Jean-Pierre (1724). Traité du Beau. Paris: Fayard, 1985.

Goodman, Nelson (1968). Languages of Art, An Approach to a Theory of Symbols, London: Oxford University Press, 1969. French translation by Jacques Morizot, Langages de l'Art. Nîmes: Chambon, 1990.

- 1978). Ways of Worldmaking. Indianapolis: Hackett Publishing Company.

Hardy, G. H. (1940). A Mathematician's Apology. Cambridge: Cambridge University Press. French translation by Julien, D. and Yoccoz, S. L'Apologie d'un mathématicien, Paris: Belin, 1985.

Hutcheson (1725). Inquiry into the Original of our Ideas of Beauty and Virtue. London: Elibron Classics series. Adamant Media Corporation, 2005.

Jullien, Caroline (2008). Esthétique et Mathématiques - Une exploration goodmanienne. Rennes: Presses Universitaires de Rennes, Collection Aesthetica.

- (2011). «Densité syntaxique et densité sémantique en mathématiques: de l'usage de la figure à la lettre». In: La figure et la lettre. Nancy: Presses Universitaires de Nancy, 173-185.

— (Forthcoming). "Poincaré et l'esthétique des mathématiques — cadre métaphysique et méthodologique». In: Actas de la Academia Nacional de Ciencias, Argentine.

Poincaré, Henri (1905). La Valeur de la science. Paris: Flammarion, 1970.

- 1908. Science et méthode. Paris: Kimé, 1999. English translation by Francis Maitland. Science and Method. New York: Cosimo, 2009.

Rota, Gian Carlo (1997). "The Phenomenology of Mathematical Beauty». Synthese, 111 (2), 171-182. 
Caroline Jullien is a researcher in philosophy of mathematics at the University of Liège and an associated member of the Laboratoire d'Histoire et de Philosophie des Sciences - Archives Henri Poincaré in Nancy (LPHS-Archives Henri Poincaré, UMR 7117 CNRS). She teaches logic and philosophy of mathematics. Her field of specialization involves the relationships between mathematics and aesthetics from a functional point of view. She is author of Esthétique et Mathématiques - une exploration goodmanienne (PUR, 2008).

Caroline Jullien es investigadora en filosofía de las matemáticas en la Universidad de Lieja y miembro asociado del Laboratoire d'Histoire et de Philosophie des Sciences - Archives Henri Poincaré a Nancy (LPHS-Archives Henri Poincaré, UMR 7117 CNRS). Imparte lógica y filosofía de las matemáticas. Su campo de especialización concierne las relaciones entre las matemáticas y la estética desde un punto de vista funcional. Es autora de Esthétique et Mathématiques - une exploration goodmanienne (PUR, 2008). 